\title{
ANALFABETO E PRECONCEITO: UMA RELAÇÃO VELADA NA SOCIEDADE
}

\author{
ILLITERATE PEOPLE AND PREJUDICE: A COVERT RELATIONSHIP IN \\ SOCIETY
}

\section{Izabel Cristina Maffioletti Jacques ${ }^{1}$}

Samira Casagrande ${ }^{2}$

\begin{abstract}
RESUMO: Este estudo tem como objetivo central fomentar um debate sobre o preconceito com o analfabeto, com o intuito de incitar uma discussão nos meios educacionais sobre esta temática, marcada por atitudes discriminatórias iguais ou maiores que os outros tantos preconceitos existentes na sociedade. Optou-se por este tema por considerá-lo de grande relevância social e por perceber que é algo subjacente na sociedade, tendo como finalidade trazer contribuições e também problematizar a atual situação existente no país relacionada ao analfabeto. Para a elaboração deste artigo foi utilizado um estudo sobre as referências teóricas publicadas sobre a problemática da pesquisa, com base em autores como Galvão e Di Pierro (2012), Schwartz (2010), Soares (2010) e Colello (2007), entres outros que discutem o analfabetismo no Brasil. Portanto, a metodologia escolhida para o estudo em questão é o estudo teórico, de cunho exploratório, sendo classificada como bibliográfica. Este trabalho apresenta considerações a respeito do preconceito contra o analfabeto, como este lida com as situações embaraçosas vivenciadas constantemente, na sequência traz a discussão do analfabetismo funcional, evidenciando as consequências para a vida do indivíduo, trazendo a importância de alfabetizar letrando nos dias atuais. Destaca ainda a Educação de Jovens e Adultos como possibilidade de exercer plenamente sua cidadania. Em suma, podemos verificar, por meio das literaturas, que as situações desagradáveis vividas pelo analfabeto lhes trazem constrangimentos, porém estes são superados constantemente por estas pessoas que desenvolveram mecanismos para sobreviver em mundo letrado.
\end{abstract}

Palavras-chave: Preconceito. Analfabeto. Analfabetismo Funcional. Educação de jovens e adultos.

ABSTRACT: This study aims at fomenting a debate on prejudice against illiterate people, with the intention of prompting a discussion, in educational circles, about this theme which is marked by discriminatory attitudes, equal or greater than many other prejudices existing in society. This topic was chosen because it is considered to be of great social relevance and, also, because it is perceived as something underpinning the society, so the purpose of this

\footnotetext{
${ }^{1}$ Pós-graduanda em Educação, Diversidade e Redes de Proteção Social - UNESC - izabelcmj@ @otmail.com

2 Mestre em Educação. sca@unesc.net

Saberes Pedagógicos, Criciúma, v. 1, n² , julho/dezembro 2017.- Curso de Pedagogia- UNESC
} 
choice was to bring contributions and also problematizing the current situation in the country related to the illiterate people. A Literature review was done based on authors as Galvão and Di Pierro (2012), Schwartz (2010) and Colello (2007), among others who have discussed the illiteracy in Brasil. The methodology used was the bibliographical study, a theoretical study of an exploratory nature. Therefore, this study presents some considerations concerning illiterate people and how they deal with the embarrassing situations faced by them constantly. Subsequently, it presents the discussion on functional illiteracy, showing its consequences for the individual's life as well as the importance of literacy and being literate nowadays. It also emphasizes Youth and Adult Education as a possibility to fully exercise their citizenship. Results show that unpleasant situations experienced by illiterate people can cause them embarrassments, but these embarrassments can be well overcome by those who have developed mechanisms which have helped them to survive in a literate world.

Keywords: Prejudice. Illiterate people. Functional Illiteracy. Youth and Adult Education.

\section{Introdução}

Estamos vivendo um momento na história da sociedade em que o preconceito, a discriminação e a exclusão social, entre as classes minoritárias, estão sendo pauta de muitas discussões entre pesquisadores e autoridades competentes. O negro, o deficiente e o homossexual estão entre as temáticas que vêm ganhando cada vez mais destaque nos debates com o objetivo de reduzir as relações sociais injustas.

Contudo, a relação do analfabeto com o preconceito é algo subjacente na sociedade. O que se percebe é que tal temática não vem sendo objeto de muitas campanhas e movimentos sociais, com a finalidade de minimizar os processos discriminatórios e excludentes que envolvem as pessoas que não tiveram a oportunidade de estudar, e que, por sua vez, não podem exercer os seus direitos plenos de cidadania.

Com base em tais argumentos, considera-se relevante discorrer sobre o objeto de estudo deste artigo, com a finalidade de contribuir e também de problematizar a atual situação existente relacionada ao analfabeto no país.

Para elaboração deste artigo procurou-se tomar como guia o seguinte problema: como as literaturas vêm tratando o preconceito com o analfabeto? A partir deste problema definiu-se como objetivo geral fomentar um debate sobre o preconceito contra o analfabeto, com o intuito de incitar uma discussão nos meios educacionais sobre esta temática, marcada

Saberes Pedagógicos, Criciúma, v. 1, n², julho/dezembro 2017.- Curso de Pedagogia- UNESC 
por atitudes discriminatórias iguais ou maiores que os outros tantos preconceitos existentes na sociedade.

A metodologia escolhida para o estudo em questão é o estudo teórico, que tem a finalidade de fomentar uma discussão sobre um tema ou questão pertinente da realidade (DEMO, 2012). Em relação aos procedimentos técnicos, se constitui como bibliográfica, porque foi "elaborada a partir de materiais já publicados, constituídos principalmente de livros, artigos de periódicos e atualmente com material disponibilizado na internet" (PINHEIRO, 2010, p. 22). Desse modo, se caracteriza como objetivo da pesquisa exploratória, por auxiliar o pesquisador na formulação de novas hipóteses para o seu problema.

Assim sendo, este trabalho organiza-se em quatro momentos: a seção 2 discorre sobre a relação entre o preconceito e o analfabeto, como este vive em uma sociedade grafocêntrica, como lida com as situações embaraçosas vivenciadas constantemente e os motivos pelos quais anseia retornar para as salas de aula.

Logo após, a seção 3 aborda a temática sobre o analfabetismo funcional, evidenciando as consequências para a vida do indivíduo, trazendo a importância de alfabetizar letrando nos dias atuais. A seção 4 apresenta a relevância da Educação de Jovens e Adultos como possibilidade de exercer plenamente a cidadania. E, por fim, a seção 5 trazendo as considerações finais acerca deste artigo.

\section{A RELAÇÃO ENTRE O PRECONCEITO E O ANALFABETO}

Um primeiro ponto a considerar, quando se discute o analfabetismo brasileiro, é que se trata de uma problemática que possui uma longa história, evidenciada por meio dos índices de analfabetismo divulgados por Censos realizados no país (PINTO et al, 2000).

\footnotetext{
Embora a taxa de analfabetismo entre a população de 15 anos ou mais venha decrescendo consideravelmente, nos últimos 80 anos, [...] a involução do número efetivo de analfabetos só foi constatada a partir da década de 1980 (COLELLO, 2007, p. 54).
} 


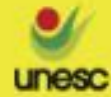

Segundo dados levantados pelo IBGE (2004), entre os anos de 1950 e 2000 foi significativo o crescimento do índice de alfabetização e o declínio do analfabetismo no Brasil. Já no ano de 2013 a taxa de analfabetismo brasileiro entre a população de 15 anos ou mais atinge a marca de $8,5 \%$, seguidos de $4,6 \%$ na região sul do país e $16,9 \%$ na região nordeste (TODOS PELA EDUCAÇÃO, 2014).

Contudo, mesmo com a redução dos índices, o analfabetismo continua sendo motivo de preocupação no cenário da educação, fazendo com que o governo brasileiro invista em programas educacionais, com a promessa de erradicação.

Iniciativas como o Movimento Brasileiro de Alfabetização (MOBRAL), os cursos supletivos, o programa Alfabetização Solidária e o programa Brasil Alfabetizado fazem parte da história do país, em busca da superação dos altos índices de analfabetismo. Todas essas políticas contribuíram para a diminuição das taxas, porém nenhuma delas evitou que chegássemos ao século XXI ainda com o índice elevado de analfabetos no Brasil (PINTO et al, 2000).

Em termos percentuais, percebe-se que o analfabetismo repercute de maneira negativa no âmbito social do país, inclusive no âmbito internacional, colocando o Brasil em posições desprivilegiadas, posicionando-o entre os piores países do mundo, quando se trata de analfabetos entre a população de 15 anos ou mais (COLELLO, 2007). Porém, muito além de posições e estatísticas, o analfabetismo reflete negativamente no âmbito individual, pois ser analfabeto não se limita ao

[...] estado ou condição de quem não dispõe da "tecnologia" do ler e do escrever: o analfabeto é aquele que não pode exercer em toda a sua plenitude os seus direitos de cidadão, é aquele que a sociedade marginaliza, é aquele que não tem acesso aos bens culturais de sociedades letradas e, mais que isso, grafocêntricas (SOARES, 2010, p. 19-20).

Portanto, segundo a autora, existe um processo de exclusão e preconceito relacionado ao analfabeto, mesmo que veladamente, pois a mesma sociedade letrada em que os analfabetos estão inseridos os exclui, privando-os de participar das práticas sociais que permeiam seu grupo social.

Nesse contexto, Galvão e Di Pierro (2012) destacam que a palavra analfabeto na sociedade contemporânea, na maioria das vezes, é carregada de significados negativos,

Saberes Pedagógicos, Criciúma, v. 1, n², julho/dezembro 2017.- Curso de Pedagogia- UNESC 


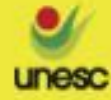

ressaltando, inclusive, que as relações sociais, de modo geral, são permeadas por preconceitos, pré-julgamentos e por estigmas. Caracterizando o sujeito por aquilo que ele não possui, pela falta de algo, atribuindo ao analfabeto a incapacidade, o despreparo, um ser sem conhecimento.

No entanto, é preciso olhar para os analfabetos como sujeitos "[...] inteligentes, que desenvolveram estratégias de sobrevivência em uma cultura escrita sem estar adequadamente instrumentalizados para isso, resolvendo problemas, vivendo, trabalhando e amando (SCHWARTZ, 2010, p. 63)”.

Mesmo que seja considerado seu processo histórico, cotidianamente a falta de domínio do código escrito muitas vezes se sobressai em relação a conhecimentos já estabelecidos, ocasionando vergonha aos analfabetos, levando-os a aceitar os estigmas impostos pela sociedade, lhes trazendo um sentimento de inferioridade, visto que

\begin{abstract}
Os sucessivos constrangimentos e experiências de discriminação levam à corrosão da auto-estima dos indivíduos, que acabam assumindo a identidade deteriorada e assimilando ao próprio discurso as metáforas depreciativas formuladas pelas elites letradas e difundidas pelos meios de comunicação social, [...] dentre as quais a mais recorrente é aquela que identifica o analfabetismo à "escuridão" da "cegueira", o analfabeto "cego", e a alfabetização à redentora "retirada da venda dos olhos" e saída das trevas da ignorância (GALVÃO; DI PIERRO, 2012, p. 24).
\end{abstract}

Esse discurso público, de cunho negativo, sobre o analfabeto, difundido nas grandes mídias, especialmente na televisão e na internet, por meio de vídeos ou gravações com teor humorístico, não leva em consideração a exclusão dos direitos das pessoas que não tiveram a oportunidade de estudar (SOUSA, 2012). E acabam, cada vez mais, fortalecendo termos pejorativos em relação ao analfabeto ${ }^{3}$ ou ao analfabetismo ${ }^{4}$.

Nesse contexto Schwartz (2010) afirma que as propostas e projetos com a finalidade de alfabetizar os jovens e adultos, executadas por diferentes segmentos da sociedade, explicitam, muitas vezes, algumas dessas representações pejorativas sobre o analfabeto. Encontramos desde o discurso de que para alfabetizar os jovens e adultos não

\footnotetext{
${ }^{3}$ Que não sabe ler nem escrever, sem instrução primária. (MICHAELIS, 2008, p. 53)

${ }^{4}$ Estado de analfabeto. (MICHAELIS, 2008, p. 53)

Saberes Pedagógicos, Criciúma, v. 1, n²2, julho/dezembro 2017.- Curso de Pedagogia- UNESC
} 


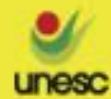

precisa ser professor a expressões como "chaga nacional” -analfabetismo não é doença! - que precisa ser "erradicada".

Dessa forma, o que se percebe é que muitas políticas públicas que visam à alfabetização do jovem e do adulto, na tentativa de minimizar tais preconceitos, acabam reforçando práticas discriminatórias já instituídas, fortalecendo assim os estigmas produzidos historicamente pela sociedade.

Compreende-se então que o preconceito e a exclusão contra o analfabeto é uma realidade presente em nosso país, e que:

\begin{abstract}
é preciso uma maior atenção das autoridades sobre esta temática, não colocando os analfabetos em situação de mais exclusão de direitos, mas revelando a sociedade uma realidade vivida e inflamada na vida de mais de 14 milhões de brasileiros. As ações devem ser muito bem analisadas, lembrando que estamos lidando com um ser de direitos, completo de sua capacidade física e intelectual. Cuidar para que as mídias sejam mais sensíveis às sátiras, cuidando para que não discriminem ainda mais estes brasileiros, que a desigualdade social impõe limites no acesso aos seus direitos básicos (SOUSA, 2012, p. 10).
\end{abstract}

Para que tais ações se concretizem é necessário que tal atitude discriminatória contra o analfabeto seja alvo de discussões, das autoridades competentes, assim como outras classes minoritárias da sociedade, como o negro, o homossexual, pessoas da classe de baixa renda, entre outras, pois tal preconceito "[...] não é alvo de muitos debates, por ser muito camuflado na sociedade, não se fala abertamente do assunto como no caso do preconceito racial" (SOUSA, 2012, p. 09).

Diante desse processo preconceituoso e excludente Galvão e Di Pierro (2012) ressaltam que não é comum pessoas analfabetas abordarem a questão como problema coletivo ou expressarem consciência da violação de seus direitos, na maioria das vezes o analfabetismo não é percebido como uma expressão de exclusão social, e sim como uma experiência individual que provoca repetidas situações de humilhação, vividas com grande sofrimento e acompanhadas por sentimentos de culpa.

Nessa perspectiva, vale destacar que para ter consciência da violação dos direitos do cidadão é necessário que se tenha conhecimento sobre tal, sendo que as leis que evidenciam tais direitos estão expostas em documentos escritos acessíveis à população, porém não podendo ser compreendidas pelo analfabeto. Desta forma, desconhecendo seus direitos o 
analfabeto não tem consciência da violação destes, atribuindo a si a responsabilidade por não saber ler e escrever, sendo excluído de diversas práticas sociais que envolvem a escrita.

São essas situações vividas diariamente pelos analfabetos, de preconceito e/ou discriminação, que os levam a se envergonhar da sua condição, fazendo-os iniciarem ou retornarem aos estudos em busca da solução do seu problema, porém em vários casos se encontra grande resistência, uma vez que:

acreditam que têm cabeça dura, que são velhos demais, incapazes, fracos das ideias, herdeiros de deficiência familiar, pois lá em casa ninguém conseguiu! Resistem, portanto, porque já tentaram outras vezes sem sucesso e internalizaram o estigma que eles é que são os culpados pela não aprendizagem, que não são inteligentes nem capazes de aprender, encontrando-se motivados para evitar situações de aprendizagem (SCHWARTZ, 2010, p. 70-71).

Sendo assim, a aprendizagem da leitura e da escrita que parece trazer diversas vantagens é negada por muitos analfabetos. E o que aparentemente parece ser tão óbvio não é, pois, segundo Schwartz (2010), os analfabetos parecem desejosos em aprender a ler e a escrever, devido às situações embaraçosas vivenciadas. Porém, o óbvio não é igual para todas as pessoas, já que o analfabeto depende de seus conhecimentos prévios e de suas experiências anteriores para concretizar suas escolhas. Ou seja, é preciso entender o analfabeto como "produtor cotidiano de riqueza material e cultural e não ignorante de saber" (GALVÃO; DI PIERRO, 2012, p. 100).

No entanto, existe ainda por parte do analfabeto o medo do desconhecido, que está intimamente ligado a situações novas, como por exemplo pagar uma conta, fazer compras em geral, reivindicar pelos seus direitos e outros, mesmo nas que parecem vantajosas. Quando conseguem superar o medo e a resistência à aprendizagem, são motivados pelas mais diversas razões, sendo que "[...] sinalizam para necessidades objetivas (ler o ônibus, a Bíblia, o jornal, escrever cartas) e para um desejo subjetivo, o de independência/autonomia" (SCHWARTZ, 2010, p. 65).

Segundo Santa Catarina (1998, p. 33), "o sonho de conquistar melhores salários, a ameaça do desemprego, a necessidade de contribuir mais eficazmente na formação dos filhos, a realização pessoal, entre outros, são fatores de peso neste processo". 
$\mathrm{O}$ retorno às salas de aula caracteriza uma tentativa de superar o discurso social de que "[...] eles representam, na sua grande totalidade, apenas a força de trabalho braçal, sendo que no sistema de valores da sociedade letrada, a contribuição do analfabeto se limita ao que ele produz com a sua força física de trabalho" (KLEIMAN, 2012, p. 268).

Schwartz (2010) ainda complementa que na base de tudo está o prazer, motivo que move o indivíduo a ir em busca do atendimento as suas necessidades. A alegria em perceber que está aprendendo e, consequentemente, que é um sujeito capaz, competente, gerando assim uma sensação de contentamento.

Podemos perceber, portanto, que, independente do motivo que leva o analfabeto a buscar instrução, ultrapassar obstáculos, vencer seus medos e superar o discurso imposto pela sociedade, o objetivo é a satisfação pessoal e a autonomia de poder ir e vir sem depender do outro, o direito de usufruir dos bens materiais, sociais, culturais e políticos de uma sociedade grafocêntrica.

\title{
3 ANALFABETISMO FUNCIONAL: UMA REALIDADE MASCARADA
}

Na busca pela superação do analfabetismo, a educação se defronta com uma problemática senão igual, ainda mais preocupante, sendo que

\begin{abstract}
ao lado do "analfabetismo absoluto", outras configurações do sujeito leitor passaram a ser objeto de preocupação entre os estudiosos da educação: o baixo letramento e o analfabetismo funcional. Esses são os casos de pessoas que, embora escolarizadas ou que, eventualmente, até dominam o princípio alfabético e as regras do sistema em questão, continuam sendo incapazes de se utilizar da escrita de modo eficiente e significativo na sociedade em que vivem (COLELLO, 2007, p. 56).
\end{abstract}

Estas pessoas passam quatro a cinco anos na escola adquirindo técnicas de leitura e escrita, mas não conseguem se apropriar dessas habilidades. Muitas vezes são incapazes de escrever um bilhete simples, de ler uma carta, analisar a fatura de água ou até interpretar uma bula de remédio, vivenciando em seu cotidiano, assim como os "analfabetos absolutos", situações embaraçosas de dependência do outro, na busca por soluções de seus problemas.

São impedidas de certo modo de participar, na sua totalidade, das práticas que envolvem a escrita, tais como: ver um filme legendado, interpretar um livro de maior Saberes Pedagógicos, Criciúma, v. 1, n², julho/dezembro 2017.- Curso de Pedagogia- UNESC 


\title{
complexidade, entre tantas outras práticas que acabam excluindo o analfabeto funcional das
} experiências que contemplam a escrita, fazendo com que o quadro de analfabetismo se amplie, tornando-se ainda mais preocupante.

Para Colello (2007, p. 57):

\begin{abstract}
Trata-se de uma problemática maciça, que não pode ser compreendida senão como um subproduto do quadro educacional brasileiro, no qual impera a escassez de recursos e de condições de trabalho, a desvalorização do professor, a burocratização do sistema, o distanciamento entre as escolas e as esferas de produção do saber, a formação precária dos educadores, o pouco conhecimento a respeito dos processos de desenvolvimento e cognição, além da inadequação e baixa qualidade do ensino.
\end{abstract}

A autora evidencia uma vasta gama de problemas na área da educação, ligados a questões sociais, culturais, políticas e econômicas, que merecem ser solucionados na sua totalidade na tentativa de resolver tal problemática, pois privilegiando um ou outro estaremos somente mascarando a situação existente.

A partir dos anos 90 o IBGE, seguindo recomendações da Unesco, passa a divulgar os índices de analfabetismo funcional baseado no número de séries escolares concluídas, e não com base na autoavaliação do respondente, como era o critério utilizado anteriormente. Segundo esse critério, a pessoa com menos de quatro anos de escolaridade passa a ser analfabeta funcional (RIBEIRO, 2006).

Contudo, se torna muito difícil garantir a veracidade das respostas nos censos realizados no país, pois independente do critério utilizado, autoavaliação ou ter por base o número de séries concluídas, vai depender da sinceridade do respondente.

Ainda assim, quatro anos de escolarização garantem a alfabetização? Sendo que é considerada alfabetizada a pessoa que utiliza a leitura e a escrita em seu contexto social e utiliza dessas habilidades para continuar aprendendo e se desenvolvendo durante a sua vida. A pergunta não tem resposta específica, pois é relativa. Depende das demandas de leitura e escrita de cada sociedade, e o que elas colocam como habilidades mínimas que todos deveriam ter (RIBEIRO, 2006).

A autora ainda coloca que a modernização das sociedades e a globalização colocam demandas cada vez maiores relacionadas à leitura e à escrita. 
A questão não é mais apenas saber se as pessoas conseguem ou não ler e escrever, mas também o que elas são capazes de fazer com essas habilidades. Isso quer dizer que além da preocupação com o analfabetismo, problema que ainda persiste nos países mais pobres e também no Brasil, emerge a preocupação com o alfabetismo, ou seja, com as capacidades e usos efetivos da leitura e escrita nas diferentes esferas da vida social (RIBEIRO, 2006, p. 01).

Nessa perspectiva, cabe salientar que tais habilidades passam a ser requeridas com mais frequência para solucionar questões burocráticas, obter emprego e desempenho profissional, e sem o domínio dessas habilidades os analfabetos, incluindo os analfabetos funcionais, além de se sentirem limitados se constrangem com a desqualificação simbólica imposta pela sociedade (GALVÃO; DI PIERRO, 2012).

Portanto, saber ler e escrever torna-se insuficiente, é preciso ir além disso. Torna-se necessário que o indivíduo não se aproprie somente dos códigos escritos, mas que também faça uso destes códigos nas práticas sociais que envolvem a escrita. Esse processo de apropriação e uso de tais habilidades - leitura e escrita - chama-se letramento (SOARES, 2010).

Diante do exposto, podemos perceber que o letramento ultrapassa as barreiras da alfabetização, como aquisição do código escrito, caminhando para a inserção do sujeito no mundo letrado, não como um sujeito neutro e estático, mas como um sujeito atuante e participativo das práticas sociais.

Nesse contexto, Soares (2010), sabendo da não neutralidade que engloba o letramento, afirma que existem interpretações conflitantes acerca da dimensão social do letramento. A autora demonstra que há uma interpretação progressista liberal, denominada "versão fraca", em que o indivíduo adquire habilidades necessárias para funcionar adequadamente em seu contexto social, e uma perspectiva radical revolucionária, denominada "versão forte", em que o letramento não é um instrumento neutro, mas um conjunto de práticas que envolvem a leitura e a escrita, geradas por processos mais amplos, responsável por reforçar ou questionar a realidade e transformar práticas sociais injustas.

Soares (2010) ainda ressalta que Paulo Freire foi um dos primeiros especialistas revolucionários a tratar do conceito de letramento, antes mesmo do seu surgimento, afirmando que se alfabetizar é utilizar a leitura e a escrita a seu favor, tomando consciência da realidade e transformando-a. Concebendo ao letramento o papel de libertação do homem, dependendo

Saberes Pedagógicos, Criciúma, v. 1, n², julho/dezembro 2017.- Curso de Pedagogia- UNESC 


\section{SABERES PEDAGÓGICOS}

Revista do Curso de Graduação de Pedagogia - Unesc

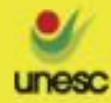

Unehos

Ca hiumaridatec.

do contexto ideológico em que está inserido, alertando para o seu caráter intrinsecamente político, defendendo que a finalidade do letramento deveria ser o de favorecer mudanças sociais.

Sendo assim, segundo o pensamento freireano, se o indivíduo se apropriar das técnicas de leitura e escrita, utilizando-as nas práticas sociais de maneira crítica, ele estará colocando em prática o que denominamos de letramento (FREIRE, 2011).

\section{EDUCAÇÃO DE JOVENS E ADULTOS: UMA QUESTÃO A SE DISCUTIR}

A alfabetização dos jovens e adultos no Brasil há algumas décadas vem sendo alvo de diferentes programas e projetos, com a promessa de erradicar o analfabetismo, porém o direito constitucional à educação somente se concretizou a partir do início da década de 90 , quando o país “" [...] foi marcado pela nova Constituição Federal de 1988, que ampliou o direito de acesso ao Ensino Fundamental para todos os cidadãos, independente da idade, colocando a EJA no mesmo grau de importância dos demais níveis de Ensino" (SANTA CATARINA, 1998, p. 33).

Desde então a alfabetização de jovens e adultos vem ganhando espaço e notoriedade em documentos oficiais que regem a educação do país, entre eles a Proposta Curricular de Santa Catarina, trazendo como destaque que:

compreender a educação como um fenômeno humano produzido em situações sóciohistóricas, num processo de conquistas e elaborações sociais de significados, nos permite apostar numa educação de jovens e adultos como direito e, não apenas a idéia de resgate da oportunidade perdida [...]. (SANTA CATARINA, 1998, p. 31).

Diante disso, podemos perceber que documentos que norteiam a educação brasileira trazem em seu texto, assim como a Proposta Curricular do Estado de Santa Catarina (1998), o reconhecimento deste nível de ensino, bem como os demais níveis, tendo por base a Constituição de 1988.

Todavia, não terá valor algum leis, programas, projetos e documentos norteadores em prol da Educação de Jovens e Adultos se não atingirem os sujeitos dentro das salas de 


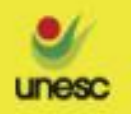

aula. Assim sendo, é necessário que os profissionais da educação e a escola se unam em defesa da mesma causa. "Afinal, embora não seja o único espaço social onde as pessoas podem se alfabetizar, a escola é a instituição à qual se atribui e de quem se cobra explicitamente a função de ensinar a ler e escrever" (GALVÃO; DI PIERRO, 2012, p. 58-59).

A escola é o lugar social onde se estabelece o contato com o sistema de escrita e com os conhecimentos científicos, ensinados de forma sistemática e organizada. Tendo por objetivo desenvolver a partir das experiências escolares o pensamento descontextualizado das experiências concretas, o que seria uma condição fundamental para o homem compreender sua cultura e agir sobre ela. A escola tem um papel central na formação do sujeito, para que ele possa atuar ativamente nas sociedades centradas na escrita. Portanto, a privação do processo de escolarização, bem como práticas escolares empobrecidas, estaria privando o sujeito de acessar as dimensões fundamentais das culturas letradas (TOLEDO, 2015). Nessa perspectiva:

a EJA se constitui como uma das modalidades de ensino que talvez melhor possua condições para contemplar a necessidade de educar indivíduos para a vida com um significado real e concreto, realizando a leitura crítica da realidade mediante os conteúdos propostos (TEIXEIRA, 2006, p. 192).

No que se refere ao profissional da educação de jovens e adultos, em especial ao professor de sala de aula, torna-se imprescindível que ele se desprenda de preconceitos, de estigmas, de representações sociais pré-estabelecidas e acredite que alfabetizar sujeitos com idade escolar avançada é possível, e, acreditando nisso, invista em práticas educativas específicas ao público-alvo, considerando:

[...] que o jovem ou adulto analfabeto não é incapaz, não é "puro" ou ingênuo, nem é uma criança crescida [...]. Nesse sentido, é preciso conhecer mais profundamente o que sabem, o que pensam e como aprendem os jovens e adultos em processo de alfabetização (GALVÃO; DI PIERRO, 2012, p. 100).

As autoras ainda complementam sobre a necessidade de o professor alfabetizador buscar formação específica para atuar junto a esse público, pois possui especificidades que os diferenciam das crianças, sendo que procedimentos didáticos inadequados e a adaptação de 
materiais do ensino fundamental regular são insuficientes, caracterizando até mesmo uma violência simbólica para os adultos (GALVÃO; DI PIERRO, 2012).

Nesse contexto, a Proposta Curricular de Santa Catarina (1998) ressalta que desenvolver uma educação de qualidade significa reorientar o processo educativo, permitindo que educador e educando interajam seus diferentes saberes sobre o mundo, realizando o processo de ensino-aprendizagem por meio do domínio da cultura e da ciência acessível à escola.

Pode-se perceber, portanto, que professor e aluno possuem conhecimentos diferenciados, porém de igual valor, por isso a relevância de respeitar o conhecimento prévio, as experiências e a bagagem cultural do analfabeto que desenvolveu estratégias de sobrevivência em um mundo centrado na escrita.

Cabe ainda salientar que

[...] a alfabetização e a educação ao longo da vida constituem um direito e não uma ação de filantropia, realizada por alguns educadores de "boa vontade". Ao lado de práticas educativas que atendam a esse público sem estigmatizá-lo, é preciso, também, realizar um esforço coletivo para a formulação de políticas públicas que ultrapassem o espírito das campanhas, estendam a oferta de ensino a essa população para as etapas posteriores à alfabetização, tornando-se, assim, permanentes e, de fato, integrantes do sistema educacional do país (GALVÃO; DI PIERRO, 2012, p. 101).

Fazendo com que os analfabetos se transformem em cidadãos autônomos, independentes, conscientes de seus direitos, utilizando o seu aprendizado nas situações do cotidiano, contribuindo para transformar as práticas sociais injustas do meio em que vivem, em especial as relacionadas ao analfabetismo. Podendo exercer o conjunto de direitos e liberdades políticas e socioeconômicas de seu país, cuidando para que seus direitos não sejam violados (PARANÁ, 2016).

De acordo com Teixeira (2006, p. 192):

Educar jovens e adultos para a vida é um desafio. Repensar quais são os objetivos, as metas, os enfoques, as epistemologias, as teorias que fundamentam a docência não é uma tarefa fácil, mas necessária. Precisa-se transformar a educação para transformar a realidade recursivamente, tornando a recíproca verdadeira. 


\section{SABERES PEDAGÓGICOS}

Revista do Curso de Graduação de Pedagogia - Unesc

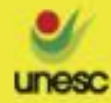

Unotice unesc

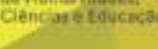

Logo, pensar e repensar a educação de jovens e adultos, significar e ressignificar as concepções do mundo vivido torna-se essencial, pois ao chegarmos à conclusão de que estamos prontos estagnaremos o pensar, o agir, o viver (TEIXEIRA, 2006).

\section{CONSIDERAÇÕES FINAIS}

A partir deste estudo foi possível perceber que o analfabetismo é algo que ainda resiste em nosso país, pois chegamos ao século XXI com taxas significativas de pessoas analfabetas no Brasil, segundo o IBGE. Pessoas estas que desenvolveram mecanismos para sobreviver em uma sociedade centrada na escrita, que amam, que pensam, que constituem família, porém muitas vezes são estigmatizadas, excluídas e discriminadas por não possuírem as habilidades de leitura e escrita.

Desse modo, esse processo preconceituoso e excludente que traz sofrimento ao analfabeto e que leva à deterioração da autoestima é algo que não se manifesta claramente na sociedade, não sendo alvo de muitos debates. Porém, as experiências constrangedoras sofridas constantemente por estes indivíduos trazem à tona uma realidade existente no país, vivida por milhões de brasileiros.

Não muito distante está o analfabeto funcional, que assim como o analfabeto absoluto é limitado de participar, na sua plenitude, das práticas que envolvem a escrita, se sentindo constrangido com a desqualificação simbólica que a sociedade lhe impõe.

Em meio a essa problemática está a educação, em especial a educação de jovens e adultos, não como a redentora, mas sim como aquela que se propõe a transformar pessoas, para que as pessoas transformem o mundo. E para que isso se concretize torna-se relevante uma educação de qualidade que alcance os sujeitos dentro das salas de aula, exigindo assim bons investimentos em todas as áreas do sistema educacional, com profissionais capacitados, que se desprendam de estigmas e preconceitos e acreditem que os analfabetos são pessoas capazes de aprender e que trazem uma bagagem cultural que precisa ser valorizada.

Profissionais que invistam em uma alfabetização não somente como aquisição do código, mas fazendo com que os alfabetizandos possam utilizar a escrita em todas as práticas que a envolvem, formando cidadãos conscientes de seus direitos e deveres.

Saberes Pedagógicos, Criciúma, v. 1, n², julho/dezembro 2017.- Curso de Pedagogia- UNESC 


\section{SABERES PEDAGÓGICOS}

Revista do Curso de Graduação de Pedagogia - Unesc

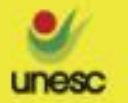

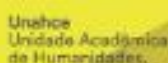

Em síntese, o analfabeto é um cidadão a quem foi negado o direito de ler e escrever, desta forma merece todo o respeito de uma sociedade por sua história de vida e superação dos embaraços que sofre diariamente.

\section{REFERENCIAS}

COLELLO, Silvia M. Gasparian. A escola que (não) ensina a escrever. São Paulo: Paz e Terra, 2007. 286p.

DEMO, Pedro. Pesquisa e construção de conhecimento: metodologia científica no caminho de Habermas. 7. ed. Rio de Janeiro: Tempo Brasileiro, 2012. 125 p.

FREIRE, Paulo. A importância do ato de ler: em três artigos que se completam. 51. ed. São Paulo: Ed. Cortez, 2011. 102 p.

GALVÃO, Ana Maria de Oliveira; DI PIERRO, Maria Clara. Preconceito contra o analfabeto. 2. ed. São Paulo: Cortez Editora, 2012. 125p.

IBGE. Tendências demográficas: uma análise dos resultados da amostra do censo demográfico 2000. Estudos e Pesquisas: Informação Demográfica Socioeconômica, n. 13, Rio de Janeiro, 2004. Disponível em:

<http://biblioteca.ibge.gov.br/visualizacao/livros/liv4889.pdf>. Acesso em: 07 out 2016.

KLEIMAN, Angela B. Os significados do letramento: uma nova perspectiva sobre a prática social da escrita. 2. ed. Campinas, SP: Mercado de Letras, 2012. 294 p.

MICHAELIS: dicionário prático da língua portuguesa. São Paulo: Editora Melhoramentos, 2008. 952 p.

PARANÁ. SECRETARIA DA JUSTIÇA, TRABALHO E DIREITOS HUMANOS - SEJU. Departamento de direitos humanos e cidadania - DEDIHC. O que é ser cidadão. 2016. Disponível em: http://www.dedihc.pr.gov.br/modules/conteudo/conteudo.php?conteudo=8. Acesso em: $16 \mathrm{dez} 2016$.

PINHEIRO, José Maurício dos Santos. Da iniciação científica ao TCC: uma abordagem para os cursos. Rio de Janeiro: Ciência Moderna Ltda, 2010. 161p.

PINTO, José Marcelino de Rezende et al. Um olhar sobre os indicadores de analfabetismo no Brasil. Revista brasileira de estudos pedagógicos, Brasília, v. 81, n. 199, p.511- 524, set./dez. 2000. Disponível em:

〈http://rbep.inep.gov.br/index.php/rbep/article/viewFile/971/945>. Acesso em: 10 out 2016. 


\section{SABERES PEDAGÓGICOS}

Revista do Curso de Graduação de Pedagogia - Unesc

RIBEIRO, Vera Masagão. Analfabetismo e alfabetismo no Brasil. Boletim INAF. São Paulo: Instituto Paulo Montenegro, jul./ago. 2006. Disponível em:

〈http://www.faccamp.br/letramento/GERAIS/analfabetismo.pdf〉. Acesso em: 02 out 2016.

SANTA CATARINA. SECRETARIA DE ESTADO DA EDUCAÇÃO E DO DESPORTO.

Proposta Curricular de Santa Catarina: Educação Infantil, Ensino

Fundamental e Médio: Temas Multidisciplinares. Florianópolis: COGEN, 1998. 120p.

Disponível em:

$\langle$ http://www.propostacurricular.sed.sc.gov.br/pdfs/PC_Temas_Multidisciplinares.pdf $>$.

Acesso em: 01 nov 2016.

SCHWARTZ, Suzana. Alfabetização de jovens e adultos: teoria e prática. Petrópolis, RJ:

Vozes, 2010. 224p.

SOARES, Magda. Letramento: um tema em três gêneros. 4. ed. Belo Horizonte: Autêntica, 2010. $125 \mathrm{p}$.

SOUSA, João Paulo Aguiar de. Analfabetismo no Brasil: história, realidade e preconceito. ABEP. Águas de Lindóia/SP. 2012. Disponível em:

$\langle$ http://www.abep.nepo.unicamp.br/xviii/anais/files/POSTER[834]ABEP2012.pdf $>$. Acesso em: 10 out 2016.

TEIXEIRA, Augusto Niche. Educação frente à complexidade, educando jovens e adultos para a vida. In: SCHEIBEL, Maria Fani; LEHENBAUER, Silvana. (Orgs). Reflexões sobre a educação de jovens e adultos. Porto Alegre: PALLOTI, 2006. p. 187-193.

TODOS PELA EDUCAÇÃO. Reportagem TPE. Analfabetismo cai de 8,7\% para 8,5\% no último ano, segundo IBGE. 2014.

Disponível em: <http://www.todospelaeducacao.org.br/reportagens-tpe/31476/analfabetismocai-de-87-para-85-no-ultimo-ano-segundo-ibge/>. Acesso em: 15 out 2016.

TOLEDO, Lucineia Silveira. Analfabetismo funcional entre adolescentes: um mal-estar na educação contemporânea. Revista Fundamentos, Piauí, v. 2, n.1, 2015. Disponível em: 〈file:///C:/Users/casa/Downloads/3763-13297-1-PB.pdf >. Acesso em: 22 out 2016. 